\title{
Proteus syndrome caused by novel somatic AKT1 duplication
}

Talal AlAnzi, FMG, Eman Al-mashharawi, MD, Amal Alhashem, FM, FMG.

\begin{abstract}

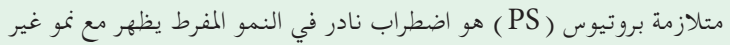

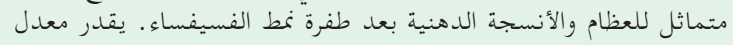

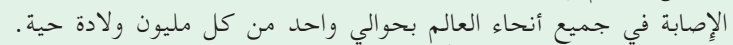

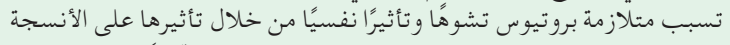

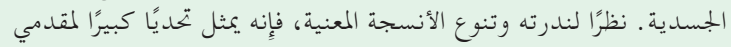

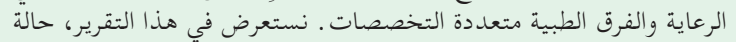

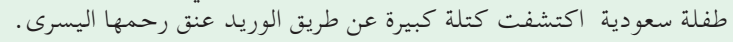

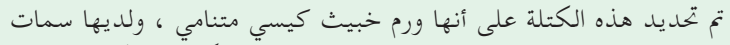

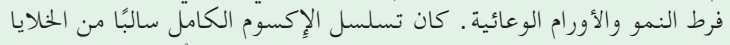

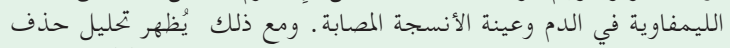

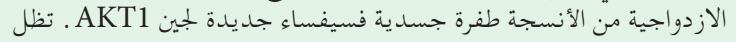

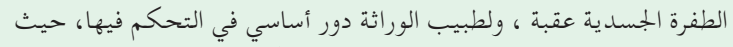
يوفر التشخيص الجيني الراسخ، والتشخيص ، ولطيب الورنة والاستشارات الأسرية.
\end{abstract}

Proteus syndrome (PS) is a rare overgrowth disorder that presents with asymmetrical growth of the bone and fat tissues following a mosaic pattern mutation. The estimated worldwide incidence is approximately one in one million live births. Proteus syndrome causes disfigurement and psychological impact through its effects on somatic tissue. Due to its rarity and diversity of tissues involved, it represents a significant challenge to caregivers and multidisciplinary medical teams. Here, we report a Saudi girl, with a large left cervical mass discovered antenatally. This mass was identified as a growing cystic hygroma, and she had features of overgrowth and hemangiomas. Whole exome sequencing was negative from the blood lymphocytes and affected tissue sample. However, deletion duplication analysis from tissue shows a novel mosaic somatic mutation of the AKT1 gene. Somatic mutation remains an obstacle, and the geneticist has an essential role in its management, providing an established genetic diagnosis, prognosis, and family counselling.

Keywords: AKT1, de novo, mosaicism, Proteus syndrome,

Saudi Med J 2021; Vol. 42 (1): 95-99 doi: 10.15537/smj.2021.1.25618
From the Department of Pediatrics (AlAnzi, Alhashem), Division of Medical Genetic; from the Department of Otolaryngology (Al-mashharawi), Prince Sultan Military Medical City, Riyadh; and from the College of Medicine (Alhashem), Alfaisal University, Riyadh, Kingdom of Saudi Arabia.

Received 13th October 2020. Accepted 6th December 2020.

Address correspondence and reprint request to: Dr. Talal AlAnzi, Department of Pediatrics, Division of Medical Genetic, Prince Sultan Military Medical City, Riyadh, Kingdom of Saudi Arabia. E-mail: talanzi@psmmc.med.sa

ORCID ID: https://orcid.org/0000-0003-0315-6759

$\mathrm{P}$ roteus syndrome (PS) is a rare medical condition that was first described in 1979 by Cohen and Hyden, and it was named Proteus after a Greek god, who was able to transform his body into multiple shapes. ${ }^{1}$ Proteus syndrome is characterized by overgrowth of many tissues that can be localized in a particular body segment or involve many areas. The affected tissues are derived from all 3 germ layers. The onset of overgrowth typically occurs in the first year of life. The skin, bones, and adipose tissue are commonly affected. ${ }^{2}$ The syndrome is a mosaic genetic syndrome that occurs de novo, with an estimated prevalence of less than one per one million. ${ }^{3}$ Proteus syndrome can be associated with bony defects, epidermal nevi, vascular tissue malformations, adipose tissue dyregulation, and lungs abnormalities. The presence of cerebriform connective tissue nevi is almost pathognomonic sign for PS. Nevi are most frequently seen on foot plantar surfaces, but have also been observed on other body parts. Approximately $10 \%$ of patients with PS have a history of epilepsy. ${ }^{4}$ Individuals with somatic mosaicism

Disclosure. Authors have no conflict of interests, and the work was not supported or funded by any drug company. 
have 2 or more genotypically distinct populations of tissues that could be contained in different parts of the body. A molecular test of mosaicism is challenging for many reasons. First, mosaicism levels can differ widely and can be difficult to detect. Second, mosaicism might be specific or limited to a tissue. Sampling from multiple tissues within an individual might be needed for revealing mosaicism, which can severely hinder analysis due to the necessary and appropriate limitations of samplings. In the case of PS, the AKT1 somatic mutation is rarely present in the lymphocytes DNA. ${ }^{5}$ In this paper, we present the first described somatic novel duplication of the AKT1 gene. All previously described individuals with clinically-confirmed PS were caused by somatic mosaicism for the specific de novo pathogenic variant c.49G>A (p.Glu17Lys). We also describe the outcome of surgical intervention in this condition.

Case Report. Patient information. Our proband is a baby girl born at 35 weeks of pregnancy by cesarian section. Antenatally, there was an abnormal mass on the left side of the neck occupying the entire neck area and extending to the ear and shoulder. The parents are first cousins with no similar history in the extended family.

Clinical findings. The planed EXIT procedure (ex utero intrapartum treatment) was conducted successfully. The baby was intubated with a size- 3 tube, and a large neck mass was noted on the left side. There was an abnormal dark pigmentation over the mass and patches over the ipsilateral bodyside, with relatively larger digits of the same side.

Upon examination, the growth parameters were within normal limits: weight, $3 \mathrm{~kg}$ (25-50th percentile); head circumference, $34 \mathrm{~cm}$ (25-50th percentile); and length, $50 \mathrm{~cm}$ (50th percentile); vitally stable; head of normal size, with anterior fontanel and palpable suture lines; normal eye exam; no nystagmus; no cleft lip or palate. There was a large, cystic, multilocular mass in the neck (non-pulsating, compressible, trans-illuminated, $10 \times 10 \mathrm{~cm}$ size, dark pigmented overlying skin, no bruit on auscultation) (Figure 1).

In the legs, there were deeply dark pigmented patches with verrucous texture-verrucous epidermal nevi, large size, and extending from the left mid-thigh to the foot with macrodactyly and syndactyly of the 2 nd and third toes (Figures $2 \& 3$ ).

The skeletal survey revealed macrodactyly of the 2 nd and 3rd toes, bilaterally. There was soft tissue syndactyly of the 2nd, 3rd, and 4th left toes and of the 2nd and 3rd right toes, and excessive soft tissue of the forefeet,

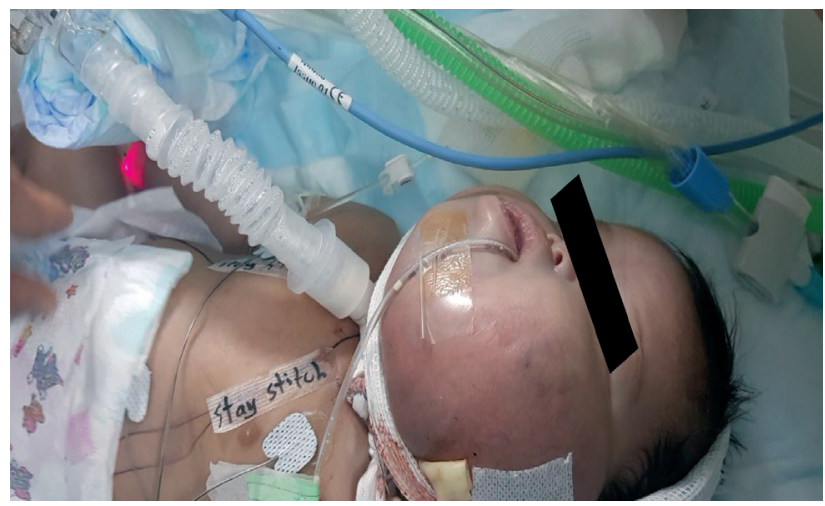

Figure 1 - Left cheek showing large cystic hygroma.

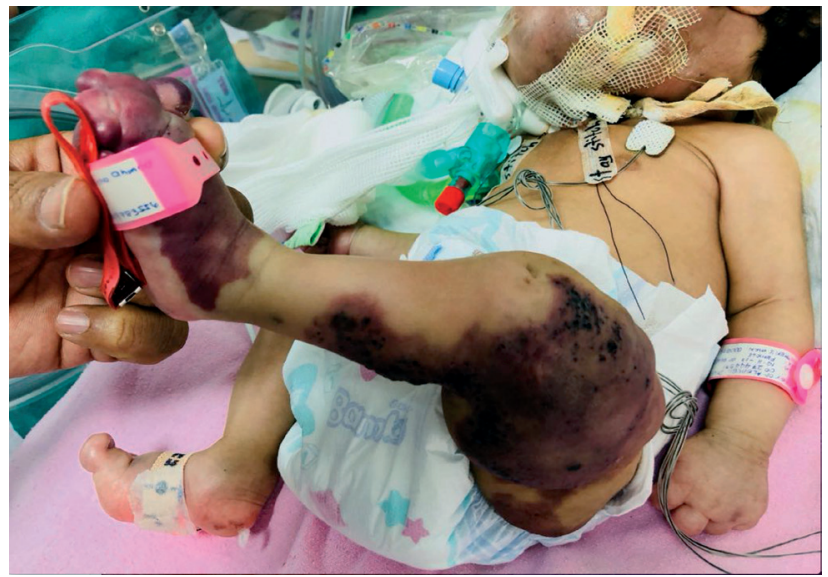

Figure 2 - Left leg showing large epidermal nevi.

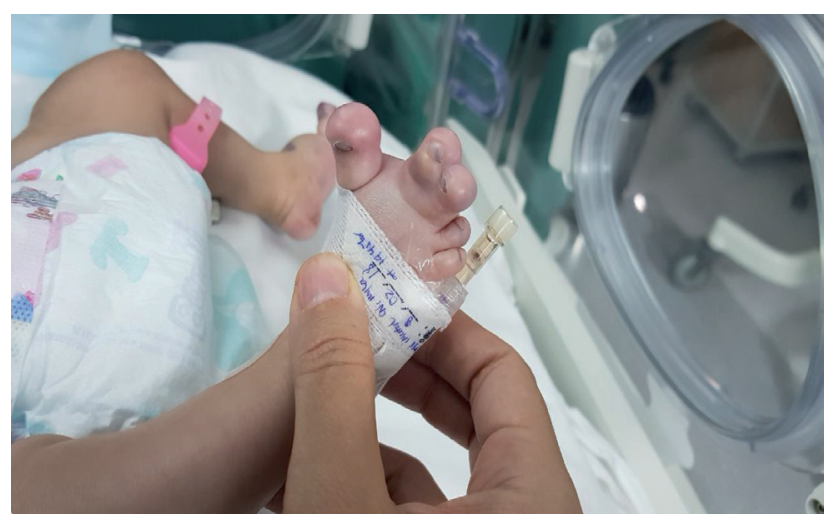

Figure 3 - Left leg showing macro-syndactyly. 


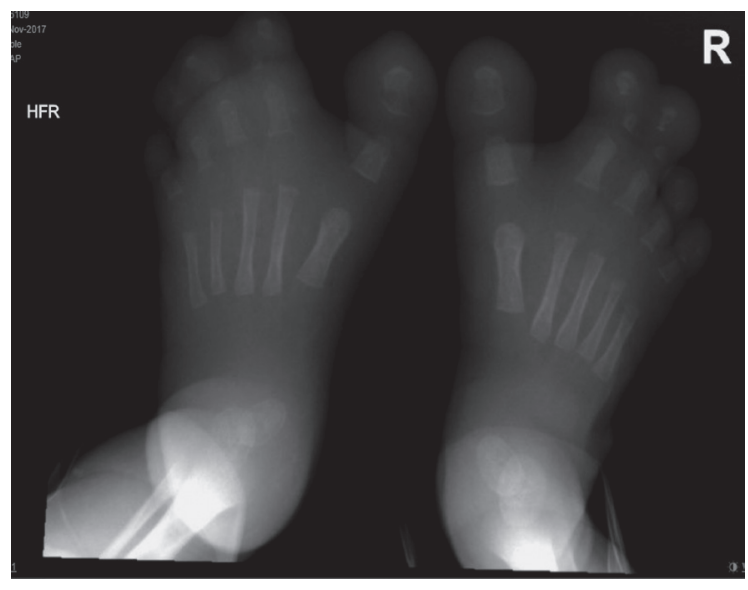

Figure 4 - X ray of the feet showing the macrodactyly.

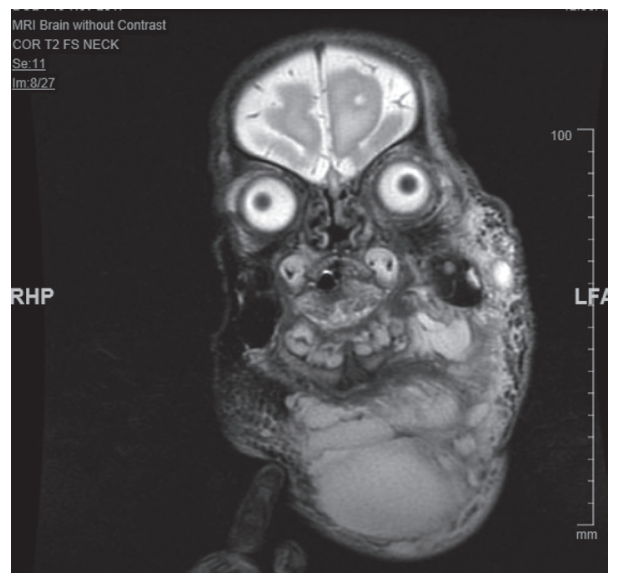

Figure 5 - Magnetic resonance imaging of the head and neck showing the large multilocular cystic hygroma.

Table 1 - Patient clinical history.

\begin{tabular}{|c|c|c|c|}
\hline Event date & Clinical presentation & Diagnostic findings & Outcome and intervention \\
\hline 19 Nov 2017 & $\begin{array}{c}\text { Born with large neck mass and body } \\
\text { overgrowth }\end{array}$ & MRI brain and neck & $\begin{array}{l}\text { Cystic hygroma, large } \\
\text { Referred to ENT }\end{array}$ \\
\hline 30 Nov 2017 & Proteus syndrome suspected & $\begin{array}{l}\text { Whole exome sequencing from } \\
\text { skin tissue }\end{array}$ & Positive AKT1 mutation \\
\hline 10 Dec 2017 & Large cystic hygroma & Abnormal MRI head and neck & $1^{\text {st }}$ sclerotherapy \\
\hline 2 Jan 2018 & Still large neck mass & Abnormal neck US & $2^{\text {nd }}$ sclerotherapy \\
\hline 7 Jan 2018 & Still large neck mass & MRI head and neck & No interval changes \\
\hline 19 Sept - 2019 & $\begin{array}{l}\text { Epileptic encephalopathy, respiratory } \\
\text { compromise }\end{array}$ & Abnormal EEG, DNR status & Passed away \\
\hline
\end{tabular}

EEG: electroencephalogram, DNR: do-not-resuscitate order, MRI: magnetic resonance imaging

bilaterally. We detected hypoplasia of the terminal phalanx of the left little toe (Figure 4). An abdominal ultrasound examination showed portal vein thrombosis.

Brain and cervical magnetic resonance imaging (MRI) showed large mixed micro and macrocystic lymphatic malformation (hygroma) with suspicion of a small venous component (Figure 5). The pediatric otorhinolaryngology team, along with the interventional radiologist, were involved in the management of the lymphatic malformation.

Therapeutic intervention. The pediatric otorhinolaryngology team decided to proceed with surgical excision and tracheostomy. The procedure was successful; however, there was a remnant of the disease mainly at the left parotid and the floor of the mouth. Furthermore, the patient underwent two sessions of sclerotherapy (using Belomycine) to control the remainder of the disease. The sclerotherapy was unsuccessful due to the nature of mixed micro-cystic diseases. The tracheostomy tube was accidentally obstructed, which caused the patient to develop severe anoxic encephalopathy and sadly pass away at 8 months old.

Diagnostic assessment. Clinically, there was a suspicion of PS because of the constellation of the phenotypic features. Whole-exome sequencing from the blood lymphocytes was negative. AKT1 gene sequencing was carried out using a skin biopsy of the affected tissue, but the result was negative. Next, an AKT gene duplication/deletion panel was performed, and the 
Table 2 - General and specific categorical criteria in order to be labelled with the diagnosis of Proteus syndrome.

\begin{tabular}{|c|}
\hline Criteria \\
\hline Positive clinical criteria \\
\hline 1. Cerebriform connective tissue nevus (5 points) \\
\hline Asymmetric, disproportionate overgrowth (one or more) 5 points \\
\hline Limbs or \\
\hline Hyperostosis of the skull or \\
\hline Hyperostosis of the external auditory canal or \\
\hline Megaspondylodysplasia, scoliosis, or rib hyperostosis \\
\hline 2. Organ/ visceral overgrowth (2 or more) 5 points \\
\hline Central nervous system or \\
\hline Urogenital system or \\
\hline Eye or \\
\hline Spleen or \\
\hline Kidney or \\
\hline Liver or \\
\hline Tonsils or adenoids or \\
\hline Gingiva or tongue \\
\hline 3. Bullae or cysts of the lungs (2 points) \\
\hline 4. Dysregulated adipose tissue (one or more) (2 points) \\
\hline Lipoma \\
\hline Lipodystrophy or \\
\hline Myocardial septal lipoma \\
\hline 5. Linear verrucous epidermal nevus (2 points) \\
\hline 6. Vascular malformation (one or more) (2 points) \\
\hline Capillary malformation or \\
\hline Venous malformation or \\
\hline Lymphatic malformation \\
\hline 7. Specific tumors (1 points) \\
\hline Female genitourinary cystadenoma ( less than 11 year old ) or \\
\hline Parotid monomorphic adenoma ( less than 11 year old ) or \\
\hline Meningioma ( meningothelial and transitional subtype ) or \\
\hline Testicular cystadenoma or cystadenocarcinoma \\
\hline 8. Facial phenotype (3 or more features) ( 2 points) \\
\hline Dolichocephaly \\
\hline Long face \\
\hline Down slanting palpebral fissures and/or minor ptosis \\
\hline Low nasal bridge \\
\hline Wide air anteverted nares \\
\hline Open mouth at rest \\
\hline 9. Deep vein thrombosis and/or pulmonary embolism (2 points) \\
\hline Negative clinical criteria \\
\hline 1. Substantial prenatal extracranial growth (minus 5 points) \\
\hline 2. Ballooning overgrowth (minus 5 points) \\
\hline Proteus syndrome diagnosis: \\
\hline $\begin{array}{l}\text { Score of } 10 \text { or more points with a mosaic AKT1 pathogenic } \\
\text { variant }\end{array}$ \\
\hline 15 or more points with or without AKT1 mutation \\
\hline $\begin{array}{l}\text { AKT1-related overgrowth spectrum: a score of 2-9 with AKT1 } \\
\text { mosaic variant }\end{array}$ \\
\hline $\begin{array}{l}\text { Geotype-phenotype approach to diagnostic criteria for Proteus } \\
\text { syndrome adopted from American Journal of Medical Genetics. } \\
\text { Copyright permission from: Turner JT, Cohen MM Jr, Biesecker } \\
\text { LG. Reassessment of the Proteus syndrome literature: application of } \\
\text { diagnostic criteria to published cases. Am J Med Genet A 2004; 130A: } \\
111-122 \text {. }\end{array}$ \\
\hline
\end{tabular}

result was heterozygous duplication encompassing exon 3 to 15 , which is novel and not previously detected in children with PS. The lab classified this variant as likely pathogenic class 2, according to the ACMG guidelines.

Follow-up and outcomes. The patient remained in the NICU for cystic hygroma management, unfortunately, she passed away due to uncontrolled epileptic encephalopathy and recurrent airway blockage by the large cystic hygroma despite two times of sclerotherapy. Do not resuscitate DNR status was discussed with the family and they agreed upon it.

Discussion. Proteus syndrome is an extremely rare disorder characterized by multiple tissues overgrowth, particularly bone and fat, vascular malformations, cerebriform lesions, or epidermal nevi. Due to its rarity and high variable phenotype, misdiagnosis of PS has been common before Biesecker first published the diagnostic criteria in 1999, which were updated by Turner in $2004 .{ }^{6}$ Patients must meet both the general criteria and the specific categorical criteria in order to be labelled with the diagnosis of PS. Our patient fulfilled these criteria (Table 2).

Lindhurst et $\mathrm{al}^{5}$ have developed new criteria for PS diagnosis, which has more sensitivity than Turner criteria $^{6}$ (Table 2).

Guidelines for the evaluation and management of the patients with PS have been elaborated, including clinical photos, skeletal X-rays of the affected body areas, computerized tomography scans, MRI, and other analyses, such as dermatology, ENT, neurology, ophthalmology, and hematology. About $20 \%$ of PS patients die prematurely from a pulmonary embolism, postoperative complications, and pneumonia. The risk of a deep venous thrombosis has to be considered when managing PS patients. The advantages and risks of a surgical procedure must be thoroughly evaluated, and all precautions must be taken if an intervention is necessary. ${ }^{6}$ Lastly, this disorder is not inherited, and it is due to a de novo mutation in the AKT1 gene, which is acquired and shows a somatic pattern.

In conclusion, PS is a rare overgrowth syndrome characterized by somatic mutation of the AKT1 gene; in our case, it is a novel variant duplication of exon 3 to 15 . Proteus syndrome can manifest as a medical emergency as it can compromise the airway. Its recurrence rate is 
near zero, as all cases show de novo mutations while the parents do not carry the mutation.

Acknowledgment. We would like to acknowledge the MRI Department of Pediatrics, Division of Medical Genetic, Prince Sultan Military Medical City, Riyadh, Kingdom of Saudi Arabia for the images and for their valuable contribution. All authors have given written permission to be acknowledged. The first and second author review the figures for clarity. Lastly, we would like to thank American Manuscript Editors (www.americanmanuscripteditors.com) for English language editing.

\section{References}

1. Popescu MD, Burnei G, Draghici L, Draghici I. Proteus Syndrome: a difficult diagnosis and management plan. J Med Life 2014; 7: 563-566.
2. Hannoush H, Sachdev V, Brofferio A, Arai AE, LaRocca G, Sapp J, et al. Myocardial fat overgrowth in Proteus syndrome. Am J Med Genet A 2015; 167: 103-110.

3. El-Sobky TA, Elsayed SM, El Mikkawy DM. Orthopaedic manifestations of Proteus syndrome in a child with literature update. Bone Rep 2015; 3: 104-108.

4. Cohen MM. Proteus syndrome review: molecular, clinical, and pathologic features. Clin Genet 2014; 85: 111-119.

5. Lindhurst MJ, Sapp JC, Teer JK, Johnston JJ, Finn EM, Peters $\mathrm{K}$, et al. A mosaic activating mutation in AKT1 associated with the Proteus syndrome. N Engl J Med 2011; 365: 611-619.

6. Turner JT, Cohen MM, Biesecker LG. Reassessment of the Proteus syndrome literature: application of diagnostic criteria to published cases. Am J Med Genet A 2004; 130: 111-122. 